\title{
The rate and cost of hospitalisation in children with sickle cell anaemia and its implications in a developing economy.
}

\author{
Samuel A. Adegoke ${ }^{1}$, Emmanuel A. Abioye-Kuteyi², Ernest O. Orji ${ }^{3}$
}

1. Department of Paediatrics and Child Health, Obafemi Awolowo University, Ile-Ife, Nigeria.

2. Department of Community Health, Obafemi Awolowo University, Ile-Ife, Nigeria.

3. Department of Obstetrics and Gynaecology, Obafemi Awolowo University, Ile-Ife, Nigeria.

\begin{abstract}
Background: There is paucity of data on the cost and rate of hospitalization in children with sickle cell anaemia (SCA) in most developing nations.

Objective: To estimate the rate and cost of hospitalization in children with SCA in Nigeria and evaluate the economic burdens on their families.

Methods: The number and duration of hospitalizations; estimated aggregate family's monthly income, cost of care and percentage of the mean annual income spent on hospitalization for each respondent were obtained using a structured questionnaire.

Results: The mean age of the 73 children was 61.1(44.3) months; M:F was 1:1.6. They had 183 admissions (average of 2.5(1.9) admissions per child per year). The mean family monthly income was $\$ 250.37$, while the average cost of care per hospitalization per subject was $\$ 132.67$. The total cost of care during the year was $\$ 24,278.37$. About one-third of the caregivers spent at least $10 \%$ of their estimated annual income as total cost of hospitalization.

Conclusion: The rate and the cost of hospitalization for children with SCA and the percentage of income spent on hospitalization were too high in our environment. Government should strengthen the National Health Insurance Scheme and subsidise the cost of care to these children.
\end{abstract}

Key words: Children, Cost, Hospitalization, Sickle Cell Anaemia

African Health Sciences 2014; 14(2):475-480

DOI: http://dx.doi.org/10.4314/ahs.v14i2.27

\section{Introduction}

Sickle Cell Disease afflicts up to 100 million people worldwide,predominantlyblackpeople(inAfrica,Europe and the America), Arabs, and those of Asian ancestry. ${ }^{1}$ In Nigeria, it is estimated that about 150,000 children are born with Sickle Cell Anaemia (SCA) annually, with a prevalence of 20 - 30 per 1000 live births, (i.e. 2 - 3\%) while that of Haemoglobin SC is approximately $0.7 \%{ }^{2,3}$ In developed countries such as Europe and America, both clinical and epidemiologic data have shown that the rates and costs of hospitalization, emergency department (ED) and outpatient visits by this group of children are substantial. ${ }^{4-6}$

\section{Corresponding author:}

Dr. Samuel Ademola Adegoke

Department of Paediatrics and Child Health, Obafemi Awolowo University, Ile-Ife, Nigeria.

E-mail: adegoke2samade@yahoo.com

Tel. No: +234803-503-7560
However, in most developing economy like Nigeria, there is paucity of data on its cost of care and the financial burden of this disease on the family of the affected children and the National health services.

In Africa, about 230,000 children are born with SCA each year, representing about 80 percent of the global burden of SCA. ${ }^{7}$ The disease account for more than six percent of all deaths in African children younger than five years. ${ }^{8}$ Most of the infant deaths due to SCA in Africa occur in West African countries, with Nigeria alone accounting for about 80 percent of these deaths. ${ }^{2}$ In most developing countries, resources to cater for SCA are inadequate, inaccessible and costly when available. ${ }^{9,10}$ This invariably contribute to the relatively high morbidities and mortality associated with SCA in these environments.

Estimating the rate and cost of hospitalizations associated with sickle cell disease will therefore form the basis for developing appropriate advocacy and interventions to limiting SCA complications and hospitalizations. Also, it will help in designing evidence- 
based health programs such as health care financing and social insurance schemes which in turn will reduce the financial burden of the disease on families.

\section{Methods}

The study was carried out at the Paediatric wards of the Ekiti State Teaching Hospital, Ado-Ekiti, Ekiti State, Nigeria. The hospital is a tertiary health institution and is the main referral facility providing both general and specialist paediatric care for many communities of south-western Nigeria. It is privately funded health institution in which patients have to pay for all categories of health care needs.

This descriptive cross-sectional study was carried out over a year (January to December, 2012). We serially documented all admissions into the paediatric wards of the hospital during the study period and studied all the sickle cell disease-related admissions. All the consecutive caregivers of sickle cell anaemic children up to the age of 15 years with haemoglobin genotype SS who were admitted at the paediatric wards of the hospital during the study period were assessed with semi structured, interviewer-administered questionnaires, after obtaining an informed consent from the caregiver. Consent was obtained for each admission. Ethical clearance was also obtained from the Ethics and Research Committee of the hospital.

The questionnaire was used to obtain information on the sociodemographic characteristics of the children such as the age, sex, parental socioeconomic class and the aggregate family's monthly income. The socioeconomic class was determined based on the occupation and the highest level of educational attainment of the parents, as recommended by Oyedeji. ${ }^{11}$ For instance, parents who are professionals with tertiary education are in class I, while unemployed or those doing menial jobs with no formal eduaction are in class V. The five classes, ranging from $\mathrm{I}$ to $\mathrm{V}$ which were generated initially were later subclassified into three major social classes, namely upper class (I and II), middle class (III) and lower class (IV and V).

The principal diagnosis, number of hospitalisations during the study period and the length of stay (in

Table I: The detailed socio-demographic characteristics of the 73 children

\begin{tabular}{lcc}
\hline Sumber of & $\begin{array}{l}\text { Percen t a e } \\
\text { children }\end{array}$ & \\
Socio-demographic variables & & 12.3 \\
\hline Age in years & 9 & 42.5 \\
$<1$ & 31 & 30.1 \\
$1-5$ & 22 & 15.1 \\
$6-10$ & 11 & 38.4 \\
$11-15$ & 28 & 61.6 \\
Sex & 45 & 26.1 \\
Male & & 20.5 \\
Female & 19 & 53.4 \\
Social class\# & 15 & \\
Upper class (I and II) & 39 & 63.0 \\
Middle class (III) & & 32.9 \\
Lower (IV and V) & & \\
Estimated aggregate monthly & 46 & 30.1 \\
income levels & 24 & 24.7 \\
$<$ National Minimum wage* & & 26.0 \\
Below Poverty threshold & & \\
Income quartile $^{*}$ & 22 & 19.2 \\
$1^{\text {st }}$ & 18 & \\
$2^{\text {nd }}$ & 19 & \\
$4^{\text {td }}$ & 14 & \\
\hline
\end{tabular}

* National Minimum wage in Nigeria as at 2012 was 120 USD

$* *$ Poverty threshold is equivalent to $1.25 \mathrm{USD}$

\# Social class was determined from the parental occupation and their highest level of educational attainment. 
days) during each hospitalisation were also obtained. We derived cost estimates by direct questioning and inspection of receipts obtained for each payment. Cost of hospitalisation included costs of investigations, drugs, blood transfusion, transportation, hospital records, surgeries and other hospital services such as consultation, nursing care, feeding and accommodation. These costs of hospitalization were added together to calculate cost of care per hospitalization. The total annual cost of care, i.e. annual costs for all hospitalisations; average cost of care per hospitalization; aggregate family's annual income and the percentage of the aggregate annual family income spent on hospitalisation were computed. Aggregate family income, i.e. the total income realised by the family, was determined by adding salaries/wages, monetary gifts and other incomes as described by the caregiver. Expenditure was calculated in United States Dollars, USD (exchange rate at the time of the study was 155 Nigeria Naira per USD). The principal source of funds for each patient was also noted. We categorized these sources as "self-pay" (i.e. out-of-pocket) and National Health Insurance Scheme (NHIS).

Data were analysed with SPSS 17.0. Simple descriptive and inferential statistics were performed and results presented in prose and tables. The proportion of annual income spent as total expenditure on care was expressed in percentages. The Effects of sociodemographic variables, rates and duration of admission on the costs of hospitalization were determined using oneway ANOVA and independent ' $\mathrm{t}$ ' tests. $\mathrm{P}$ value $<0.05$ was taken as statistical significance at 95\% confidence interval.

\section{Results}

Socio-demographic characteristics of the children A total of 73 SCA children were admitted during the study period. Their ages ranged from 6 to 180 months, with a mean (SD) of $61.1 \pm 44.3$ months. There were nine $(12.3 \%)$ infants among them. The male to female ratio was 1: 1.6.

\section{Socio-economic status of the caregivers}

Majority, 39 (53.4\%) were from the lower social classes (IV - V), and only 19 (26.0\%) were from the upper social classes (I and II). The monthly income of the caregivers ranged from $\$ 9.68$ to $\$ 1,632.26$, with mean (SD) of $\$ 250.37 \pm \$ 272.92$. Table I shows the detailed socio-demographic characteristics of the children. About two-third, (63.0\%) of the subjects' families earned below the national monthly minimum wage of $\$ 120$, and about one-third, (32.9\%) were living below poverty threshold of $1.25 \mathrm{USD}$ per day.

Table II: The detailed rates and duration of hospitalization of the SCA children.

\begin{tabular}{cll}
\hline Criteria & $\begin{array}{l}\text { Number of } \\
\text { children }\end{array}$ & $\begin{array}{l}\text { Percentage } \\
\mathbf{( \% )}\end{array}$ \\
\hline $\begin{array}{l}\text { Number of hospitalization } \\
\text { per year }\end{array}$ & & \\
Once & 31 & 42.5 \\
Twice & 16 & 21.9 \\
Thrice & 8 & 11.0 \\
> Thrice & 18 & 24.7 \\
Duration of hospitalization & & \\
< 3 days & 6 & 8.2 \\
3-6 days & 18 & 24.7 \\
1 week - 1 month & 45 & 61.6 \\
$>1$ month & 4 & 5.5 \\
\hline
\end{tabular}

\section{Rates and duration of hospitalization of SCA children}

The 73 SCA children had a total of 183 admissions, with rate ranging from one to eight and mean (SD) of $2.5 \pm 1.9$ admissions per child. The median hospitalization rate was 2. More than half of the subjects were admitted more than once and about one quarter was admitted more than three times in the 12 months period of study as shown in Table II.

The average length of stay on admission was $7.8 \pm$ 3.1 days per child per admission (per year), and a total of 1056 days of care per year. The length of stay ranged from one to 52 days; and about two-third of the children $[49(67.1 \%)]$ were on admission for more 
than one week. Table II shows the detailed rates and duration of hospitalization of the SCA children.

\section{Cost of hospitalization}

As at year 2012, the average cost per hospitalization was $\$ 132.67 \pm \$ 95.24$; with a range of $\$ 69.54-\$ 320.83$. Hence, the total annual cost of hospitalizations for the 73 sickle cell anaemic children was $\$ 24,278.37$; with a mean annual cost of $\$ 332.58 \pm \$ 287.59$ per child.

The mean (SD) cost per hospitalization for children with vaso-occlusive crisis only was $\$ 140.64 \pm \$ 91.69$, ranging from $\$ 48.65$ to $\$ 201.61$. For those with anaemic crisis only, the cost of hospitalisation ranged from $\$ 82.90$ to $\$ 230.19$, with a mean cost of 163.32 $\pm \$ 74.42$. The three children with cerebrovascular disease spent a mean cost per hospitalization of $\$ 621.72 \pm \$ 275.86$.

In $137(74.9 \%)$ of the 183 admissions, the payment for care was "out-of-pocket" and in the remaining 46 $(25.1 \%)$, NHIS was utilized. Of those self-sponsored, $29(21.2 \%)$ had to take a loan to meet the cost of admission. From table III which shows the cost of hospitalization by the categories of payment, expenditure on drugs was the highest $(38.5 \%)$.

Proportion of family annual income spent on hospitalization

The proportion of annual income spent as total expenditure on care ranged from 1.2 to $117 \%$, with a mean of $25.1 \pm 19.3 \%$. Majority of the families, $46(63.0 \%)$, spent $<10 \%$ of their annual income on hospitalization, and $14(19.2 \%), 8(11.0 \%)$ and $5(6.8 \%)$ spent $10-49 \% ; 50-99 \%$ and $\geq 100 \%$ of their annual income on hospitalization respectively. Hence, about a-third of the caregivers, $27(37.0 \%)$, spent at least $10 \%$ of their annual income for hospitalizing their children with SCA.

Effects of socio-demographic variables, rates and duration of admission on the cost of hospitalization

As expected, age and the estimated family monthly income were not associated with cost of care $(\mathrm{P}=$ 0.091 and 0.639 respectively, using one-way ANOVA). Also, although females incurred higher mean total cost of care than males, the difference was not significant statistically $(P=0.240)$. Social class was also not associated with cost of care $(\mathrm{P}=0.170)$. (Table IV).

Table III: Cost of hospitalization by categories of payment during the study period

\begin{tabular}{lccc}
\hline $\begin{array}{l}\text { Categories of } \\
\text { payment }\end{array}$ & $\begin{array}{c}\text { Annual cost of } \\
\text { Care ( in USD) }\end{array}$ & $\begin{array}{c}\text { \% of the Total } \\
\text { Annual cost }\end{array}$ & $\begin{array}{c}\text { Average cost of care per } \\
\text { hospitalization(in USD) }\end{array}$ \\
\hline Tnvestigations & $3,847.25$ & 15.8 & 21.02 \\
Drugs & $9,337.49$ & 38.5 & 51.02 \\
Blood transfusion & $2,724.40$ & 11.2 & 14.89 \\
Transportation & $2,372.05$ & 9.8 & 12.96 \\
Surgeries & $1,334.28$ & 5.5 & 7.29 \\
Others* & $4,662.91$ & 19.2 & 25.48 \\
\hline Total Annual cost & $\mathbf{2 4 , 2 7 8 . 3 7}$ & $\mathbf{1 0 0 . 0}$ & $\mathbf{1 3 2 . 6 7}$ \\
\hline
\end{tabular}

NB: *Others refer to costs of hospital records, nursing charges, accommodation and feeding

On the other hand, the rate of hospitalization and the length of hospital stay were positively associated with total hospitalization costs. The average total cost for patients with hospital stays of $<7$ days was $\$ 158.51$ less than for patients with hospital stays of $\geq 7$ days $(\mathrm{P}=0.026)$. Similarly, the average total cost for children with more than one admission was $\$ 331.21$ higher than for those with only one admission $(\mathrm{P}=<0.001)$.

\section{Discussion}

The management of SCA consumes a sizeable proportion of medical resources in most African countries, as shown in this study. About 25 percent of the children were admitted on more than three occasions for SCArelated problems during the study period. The rate of 
hospitalization for some children was as high as eight times in the 12 months study period. Also, we found that the average family expenditure per hospitalization associated with sickle cell anaemia is substantial and that majority of the caregivers pay this cost at the point of care. As observed by some other researchers, ${ }^{12,13}$ a high level of expenditure on care of a particular illness may lead to a cut back on other recurrent family expenditures such as feeding, clothing and housing, which in turn will affect the quality of life of the family. Most probably, other children in the family will be severely affected because the family income is diverted to the care of their siblings with SCA.

In this study, the average cost of care per hospitalization was estimated at $\$ 132.67 \pm 95.24$, in a country where more than 70 percent of the population earn less than one U.S. dollar per day and spend more than 40 percent of their total income to satisfy hunger. ${ }^{14}$ This high cost of care also reflects what happen in most developed economies where the total direct yearly cost of hospitalization for children with SCA is also high. ${ }^{15}$ The cost of care for individuals with SCA also varies with the severity of disease manifestations. A recent study by the National Association of Children's Hospitals and Related Institutions in the United States of America ${ }^{16}$ found that annual charges for children with mild SCA were less than $\$ 10000$, whereas individuals with severe manifestations, including stroke incurred charges of approximately $\$ 70000$ per year. In low income economies where funds are not readily available for care, simple and cost-effective interventions that are geared towards limiting the incidence of severe complications of SCA must be put in place. Such interventions include early identification of SCA patients through newborn screening and provision of comprehensive care such as prompt treatment of acute events and prophylaxis against infections, mainly with oral penicillin and vaccination against Streptococcus pneumonia. ${ }^{17}$

In addition to the high cost of care, families of children with SCA tend to lose business opportunities and absent themselves from work in order to take care of the affected child. This further worsens the financial difficulties of the family. In this study, in 21.1 percent of 'self-sponsored' admissions, the caregivers had to take a loan to meet the cost of care. Brown et al, ${ }^{18}$ in a recent assessment of impact of sickle cell disease on carers at the University Teaching Hospital, Ibadan, Nigeria, stated that family finances were adversely affected in more than half of the families, with some of them needing financial help from outside in form of loan to care for their children.

Periodic estimates of the cost of care in children with SCA are highly desirable. Firstly, it facilitates the assessment of the value of new treatments and treatment strategies. Cost of care estimates also allow health care payers to plan for the needs of their patients with SCA. Information about the cost of care in SCA may inform the prioritization of research efforts. Sadly, in Africa where the greater burden of sickle cell syndrome exist, such data to estimate the cost of care in this group of children has been scanty.

Although accurate determination of family income could be subject to recall bias and only 73 children with SCA were studied, their rate and duration of hospitalization as well as the cost of care were rather too high. To limit these, government must support research to develop interventions which can prevent sickle cell crisis and limit hospitalization rate. Those interventions such as pneumococcal vaccination and use of hydroxyurea undoubtedly have great potential for saving health care costs. In sub-Saharan African where malaria infection is the leading trigger of crisis in children with SCA, efforts to curtail malaria will not only reduce mortality associated with SCA, but will also reduce rates and costs of hospitalization in them. The use of insecticide treated nets, generous and regular intake of fruits and aggresive environmental manipulations such as regular clearing of drainages or stagnant water and bush clearing are highly desirable. Recently, in a recent experimental study on the influence of lime juice on the severity of SCA, ${ }^{19}$ daily intake of lime juice for six months was found to limit the rate of bone pain crisis, febrile illness and hospitalization in these children. Government should also strengthen the NHIS as well as subsidising the cost of SCA care to alleviate the huge financial burden on the family. NHIS will increase access of this group of children to health care and also protect them against the risk of incurring huge and unaffordable medical expenses. National and State governments should also develop, implement and strengthening SCD policies to enhance care. These policies should focus on routine neonatal screening for SCD, life-long comprehensive care to minimize morbidity and mortality and community education.

\section{Acknowledgement:}

We thank all our colleagues who were involved in the management of these children. 


\section{References}

1. Serjeant GR. Epidemiology of Sickle Cell Disease. In: Sickle Cell Disease. Oxford University Press, New York; 1988; $2^{\text {nd }}$ eds. pp. 379-84.

2. World Health Organisation: Sickle-Cell Anaemia Report by the Secretariat. Fifty ninth world Health Assembly; 2006; http://apps.who.int/gb/ebwha/pdf_ files/WHA59/A59_9-en.pdf.

3. Akinyanju OO, Otaigbe AI, Ibidapo MOO. Outcome of holistic care in Nigerian patients with Sickle Cell Anaemia. Clin. Lab. Haem. 2005;27:195-9.

4. Mvundura M, Amendah D, Kavanagh PL, Sprinz PG, Grosse SD. Health care utilization and expenditures for privately and publicly insured children with Sickle Cell Disease in the United States. Pediatr Blood Cancer 2009;53(4):642-6.

5. Amendah D, Mvundura M, Kavanagh PL, Sprinz PG, Grosse SD. Sickle Cell Disease-related pediatric medical expenditures in the U.S. Am. J Prev Med. 2010;38(4):S550-6.

6. Kauf TL, Coates TD, Huazhi L, Mody-Patel N, Hartzema AG. The cost of health care for children and adults with Sickle Cell Disease. Am J Hematol 2009; 84(6):323-7

7. Modell B, Darlison M. Global epidemiology of Haemoglobin disorders and derived service indicators. Bull World Health Organ. 2008;86(6):480-487.

8. McAuley CF, Webb C, Makani J, Macharia A, Uyoga S; Opi DH et al: High mortality from Plasmodium falciparum malaria in children living with Sickle Cell Anaemia on the coast of Kenya. Blood 2010;116:16631668.

9. Akinyanju O, Johnson AO. Acute illness in Nigerian children with sickle cell anaemia. Ann Trop Paedatr 1987;7:181-186.

10. Anie KA, Egunjobi FE, Akinyanju OO. Psychosocial impact of Sickle cell disorder: Perspectives from a
Nigerian setting. Globalization and Health 2010; 6(2): $1-6$.

11. Oyedeji GA. Socioeconomic and cultural background of hospitalized children in Ilesa. Nig J Paediatr 1985; 13: 111 - 17.

12. Sadoh WE, Oviawe O. The economic burden to families of HIV and HIV/Tuberculosis coinfection in a subsidized HIV treatment program. J Natl Med Assoc 2007;99:627-31.

13. Sadoh WE, Nwaneri DU, Owobu AC. The cost of out-patient management of chronic heart failure in children with congenital heart disease. Niger J Clin Pract 2011;14:65-9

14. World Bank Report: World Development Indicators and Global Development Finance; 2011; http:// databank.worldbank.org/ accessed 19 December, 2011.

15. Davis H, Moore R, Gergen P. Cost of hospitalizations associated with sickle cell disease in the United States. Public Health Rep. 1997; 112: 40-43.

16. Sarnaik SA, Lusher JM. Neurological complications of sickle cell anaemia. Am J Pediatr Hematol Oncol. 1982; 4: 386-394.

17. Grosse SD, Odame I, Atrash HK, Amenda DD, Piel FB, William TN. Sickle Cell Disease in Africa: a neglected cause of early childhood mortality. Am J Prev Med. 2011;41 (6 Suppl 4):S398-405.

18. Brown B., Okereke J., Lagunju I., Orimadegun A., Ohaeri J. and Akinyinka O. Burden of health-care of carers of children with sickle cell disease in Nigeria. Health \& Social Care in the Community 2010; 18: 289_ 295.

19. Adegoke SA, Shehu UA, Mohammed LO, Y Sanusi, and Oyelami OA. Influence of lime juice on the severity of Sickle Cell Anaemia. J Altern Complement Med. 2013;19(6):588-92. 